\title{
EXIGÊNCIAS LEGAIS PARA A ATUAÇÃO DE PROFESSORES NOS ANOS INICIAIS DO ENSINO FUNDAMENTAL (1996-2019)
}

\author{
EXIGENCIAS LEGALES PARA LA ACTUACIÓN DE PROFESORES EN LOS AÑOS \\ INICIALES DE LA EDUCACIÓN BÁSICA (1996-2019)
}

\section{LEGAL REQUIREMENTS FOR TEACHERS' ACTION IN THE EARLY YEARS OF FUNDAMENTAL EDUCATION (1996-2019)}

\author{
Darbi Masson SUFICIER ${ }^{1}$ \\ Mariana Passafaro Mársico AZADINHO ${ }^{2}$ \\ Luci Regina MUZZETI ${ }^{3}$
}

RESUMO: O objetivo do artigo é apresentar, de forma cronológica, as alterações nas exigências formativas para a atuação nos anos iniciais do ensino fundamental contidas na legislação após a promulgação da Lei no 9.394/1996. Evidencia-se que a exigência da formação superior para atuar nesse nível de ensino é abrandada e relativizada ao longo do tempo, com a manutenção da admissibilidade da formação no Curso Normal Médio/Magistério. Assim, as diretrizes atuais para a formação de professores para os anos iniciais do ensino fundamental são semelhantes àquelas presentes na LDB promulgada há mais de duas décadas.

PALAVRAS-CHAVE: Formação de professores para os anos iniciais do ensino fundamental. Legislação educacional. Pedagogia. Normal Superior. Curso Normal Médio/Magistério.

RESUMEN: El propósito del artículo es presentar, en forma cronológica, los cambios en los requisitos de capacitación para la actuación de los profesores en los primeros años de educación básica, comprendidos en la legislación después de la promulgación de la Ley $n^{\circ}$ 9.394/1996. Se ha evidenciado que la exigencia de formación profesional superior para trabajar en este nivel de educación es ablandada y se relativizada con el tiempo, por medio del mantenimiento de la admisibilidad de la capacitación en la Escuela Normal/Magisterio. Así, las directrices actuales para la capacitación de los profesores para los primeros años de la escuela básica son similares a aquellas presentes en la $L D B$, promulgada hace más de dos décadas.

PALABRAS CLAVE: Capacitación de los profesores para los primeros años de la escuela primaria. Legislación educativa. Pedagogía. Normal Superior. Escuela Normal/Magisterio.

${ }^{1}$ Universidade Estadual Paulista (UNESP), Campus Araraquara, Araraquara - SP - Brasil. Pesquisador PNPD. Doutor em Educação Escolar (UNESP). ORCID: https://orcid.org/0000-0002-8476-9559. E-mail: darbimassonsuficier@hotmail.com.

${ }^{2}$ Faculdade de Taquaritinga (FTGA), Taquaritinga - SP - Brasil. Mestranda no Programa de Pós-Graduação em Educação Sexual. ORCID: http://orcid.org/0000-0002-8489-7358.E-mail: mamarsico@gmail.com.

${ }^{3}$ Universidade Estadual Paulista (UNESP), Campus Araraquara, Araraquara - SP - Brasil. Professora Livre Docente no Departamento de Didática. ORCID: https://orcid.org/0000-0002-6808-2490. E-mail: luci.muzzeti@unesp.br.

RPGE- Revista on line de Política e Gestão Educacional, Araraquara, v. 24, n. 3, p. 1461-1473, set./dez. 2020. e-ISSN:1519-9029 DOI: https://doi.org/10.22633/rpge.v24i3.13597 
ABSTRACT: The aim of this article is to present, in chronological form, the changes in the formative requirements for the performance of teachers in the early years of elementary education, comprised in the legislation after the enactment of Law no. 9,394/1996. It becomes evident that the demand for higher education to work at this level of education is eased and relativized over time, maintaining the admissibility of the formation in the Normal School/ Teacher-training colleges. Thus, the current guidelines for teacher-formation in the early years of elementary school are similar to those present in the $L D B$, promulgated more than two decades ago.

KEYWORDS: Teacher-formation for the early years of fundamental education. Education legislation. Pedagogy. Normal School. Teacher formation colleges.

A exigência de formação específica para os professores que atuam nos anos iniciais do ensino fundamental sofreu diversas alterações desde a promulgação da Lei de Diretrizes e Bases da Educação Nacional (LDB), a Lei no 9.394, de 23 de dezembro de 1996 (BRASIL, 1996a). O presente artigo analisa essas alterações e tem como fonte de dados a legislação e demais documentos oficiais do Ministério da Educação.

O texto promulgado em 1996 define a formação do professor para a educação básica, em seu artigo 62, considerando que a:

A formação de docentes para atuar na educação básica far-se-á em nível superior, em curso de licenciatura, de graduação plena, em universidades e institutos superiores de educação, admitida, como formação mínima para o exercício do magistério na educação infantil e nas quatro primeiras séries do ensino fundamental, a oferecida em nível médio, na modalidade Normal (BRASIL, 1996a).

O referido artigo estabelece a formação do professor em nível superior para atuar na educação básica e, ao mesmo tempo, explicita também que a formação mínima exigida para atuar como professor na educação infantil e nas séries iniciais do ensino fundamental é o Ensino Médio Normal/Magistério. Nas palavras de Pinheiro e Romanowski (2010, p. 148): “O anúncio da formação mínima em curso superior é um avanço, no entanto, não em plenitude ao manter o nível médio".

A proposta inicial da LDB era de que, no prazo de 10 anos, o país contaria, nesse nível de ensino, apenas com professores com formação de nível superior. No caput do artigo 87 do diploma legal, ficou instituída a: "Década da Educação, a iniciar-se um ano a partir da publicação desta Lei”, ou seja, a partir de 23 de dezembro de 1997 até 23 de dezembro de 2007. No $\S 4^{\circ}$ do mesmo artigo constava que: “Até o fim da Década da Educação somente serão admitidos professores habilitados em nível superior ou formados por treinamento em serviço". 
Com isso, conforme previsto no art. 62, a formação de nível médio na modalidade Normal seria aceita como requisito mínimo para a atuação na educação infantil e nos anos iniciais do ensino fundamental. Por sua vez, o art. $87, \S 4^{\circ}$ estabeleceu o prazo de dez anos para que os professores em exercício obtivessem a certificação no nível superior.

No dia seguinte após a publicação da LDB, foi promulgada a Lei nº 9.424/1996 (BRASIL, 1996b), a qual criou o Fundo de Manutenção e Desenvolvimento do Ensino Fundamental e de Valorização do Magistério, o FUNDEF. Em seu art. $9^{\circ}$, § $2^{\circ}$, foi estabelecido novamente um prazo para a obtenção de certificação, neste caso para professores sem qualquer formação: “Aos professores leigos ${ }^{4}$ é assegurado prazo de cinco anos para obtenção da habilitação necessária ao exercício das atividades docentes".

Nesse sentido, ainda sem a regulamentação do artigo 62 da LDB, a Câmara de Educação Básica do Conselho Nacional de Educação publicou a Resolução CEB nº 2, de 19 de abril de 1999 (BRASIL, 1999a) que trazia no caput de seu artigo $1^{\text {o: }}$ :

O Curso Normal em nível Médio, previsto no artigo 62 da Lei 9394/96, aberto aos concluintes do Ensino Fundamental, deve prover, em atendimento ao disposto na Carta Magna e na Lei de Diretrizes e Bases da Educação Nacional, LDBEN, a formação de professores para atuar como docentes na Educação Infantil e nos anos iniciais do Ensino Fundamental, acrescendo-se às especificidades de cada um desses grupos as exigências que são próprias das comunidades indígenas e dos portadores de necessidades educativas especiais (BRASIL, 1999a, Art. $1^{\circ}$ ).

Apesar disso, em 6 de dezembro de 1999, o artigo 62 da LDB foi regulamentado por meio do Decreto $n^{\circ} 3.276$, o qual dispôs sobre a formação em nível superior de professores para atuar na educação básica, definindo a exigência de formação superior para a atuação nos anos iniciais do ensino fundamental:

A formação em nível superior de professores para a atuação multidisciplinar, destinada ao magistério na educação infantil e nos anos iniciais do ensino fundamental, far-se-á exclusivamente em cursos normais superiores (BRASIL, 1999b, Art. $3^{\circ}, \S 2^{\circ}$ ).

Por meio deste decreto foi criado o Curso Normal Superior, única formação de nível superior que seria aceita para o exercício profissional nos anos iniciais do ensino fundamental. Conforme atesta o Parecer CNE no 970/1999, do CNE (BRASIL, 1999c), a LDB normatizou que, com o prazo estabelecido de 10 anos, os professores desse nível de ensino deveriam ter a certificação no Curso Normal Superior (BRASIL, 1996a, Art. 62 e Art. 87, § 4º). Por sua vez,

${ }^{4}$ Aqueles que exercem o magistério sem a devida habilitação e, portanto, em caráter precário.

RPGE- Revista on line de Política e Gestão Educacional, Araraquara, v. 24, n. 3, p. 1461-1473, set./dez. 2020. e-ISSN:1519-9029 DOI: https://doi.org/10.22633/rpge.v24i3.13597 
a atuação dos profissionais com diploma em Pedagogia foi estabelecida no artigo 64 da referida lei:

A formação de profissionais de educação para administração, planejamento, supervisão e orientação educacional para educação básica, será feita em cursos de graduação em Pedagogia ou em nível de pós-graduação, a critério da instituição de ensino, garantida, nesta formação, a base comum nacional (BRASIL, 1996a, Art. 64).

Com isso, os detentores de diploma em Pedagogia ficaram inabilitados para o exercício do magistério, o que foi alterado no ano seguinte, possibilitando novamente a atuação desses profissionais. Conforme se verifica na Figura 1, ocorreu um aumento significativo na oferta de cursos de Pedagogia e de Normal Superior e, consequentemente, no número de matrículas.

Figura 1 - Quadro do número de cursos de formação, matrículas e concluintes para a atuação nos anos iniciais do ensino fundamental

\begin{tabular}{|c|c|c|c|c|c|}
\hline & \multirow{2}{*}{ Curso } & \multirow{2}{*}{$\begin{array}{l}\text { Quantidade de } \\
\text { cursos }\end{array}$} & \multirow{2}{*}{ Matrículas* } & \multicolumn{2}{|c|}{ Concluintes no ano anterior } \\
\hline & & & & Do curso & Total \\
\hline 1996 & Pedagogia & 513 & 123.700 & 26.159 & 26.159 \\
\hline \multirow[b]{2}{*}{2000} & Pedagogia & 837 & 202.584 & 31.027 & \multirow[b]{2}{*}{32.380} \\
\hline & $\begin{array}{l}\text { FPED }^{1} \\
(\text { N. S. })^{2}\end{array}$ & $\begin{array}{l}110 \\
(20)\end{array}$ & $\begin{array}{l}15.385 \\
(1.166)\end{array}$ & $\begin{array}{c}1.353 \\
(0)\end{array}$ & \\
\hline \multirow{3}{*}{2004} & Pedagogia & 1.437 & 278.026 & 66.793 & \multirow{3}{*}{109.869} \\
\hline & $\mathrm{EAD}^{3}$ & $33^{4}$ & 35.528 & 12.938 & \\
\hline & $\begin{array}{l}\text { FPED } \\
\text { (N. S.) }\end{array}$ & $\begin{array}{c}996 \\
(701) \\
\end{array}$ & $\begin{array}{l}106.933 \\
(69.212) \\
\end{array}$ & $\begin{array}{c}30.138 \\
(10.385) \\
\end{array}$ & \\
\hline \multirow[b]{2}{*}{2008} & Pedagogia & 1.636 & 278.677 & 55.290 & \multirow[b]{2}{*}{74.726} \\
\hline & $\begin{array}{l}\text { FPED } \\
\text { (N.S.) }\end{array}$ & $\begin{array}{c}426 \\
(373)\end{array}$ & $\begin{array}{c}33.742 \\
(28.228) \\
\end{array}$ & $\begin{array}{c}19.436 \\
(17.847) \\
\end{array}$ & \\
\hline \multirow{4}{*}{2012} & Pedagogia & 1724 & 307.564 & 56.735 & \multirow{4}{*}{56.735} \\
\hline & Pedagogia EAD & 110 & 295.702 & 55.402 & \\
\hline & FPED & 66 & 5203 & 157 & \\
\hline & FPED EAD & 1 & 593 & 0 & \\
\hline \multirow{2}{*}{2018} & Pedagogia & 1495 & 269.787 & 52.546 & \multirow{2}{*}{122.478} \\
\hline & Pedagogia EAD & 232 & 478.103 & 69.932 & \\
\hline
\end{tabular}

* O número de matrículas corresponde ao número de estudantes matriculados no curso naquele ano, independente do ano de ingresso.

${ }^{1}$ FPED - Formação de Professor da Educação Básica: cursos com diferentes denominações, inclusive Normal Superior (N. S.).

${ }^{2}$ O Curso Normal Superior passou a compor o Censo da Educação Superior em 1999.

${ }^{3}$ No Censo da Educação Superior de 2000 aparece a primeira menção aos cursos à distância.

4 Educação à Distância: 8 cursos de Pedagogia, 20 de Normal Superior e 5 de Formação de professor das séries iniciais do ensino fundamental (Cf. 2020a, Sinopse da Educação Superior 2004, tabela 7.1). Fonte: INEP, 2020a (Sinopses Estatísticas da Educação Superior 1996-2018): 1996 (tabela 4.5); 2000 (tabelas 3.2 e 6.2); 2004 (tabelas 3.2 e 4.5); 2008 (tabelas 4.5 e 5.2); 2012 (tabelas 3.2, 5.2, 6.2, 7.4, 7.6 e 7.7$) ; 2018$ (tabelas $1.14,3.2,6.2$ e 7.4 ).

Fonte: INEP (2020) - adaptado pelos autores

Em 07 de agosto de 2000, oito meses após a publicação da regulamentação, foi promulgado o Decreto $n^{\circ} 3.554$, que alterou a redação do Art. $3^{\circ}$, § $2^{\circ}$ do Decreto no 3.276/1999, determinando que: 
A formação em nível superior de professores para a atuação multidisciplinar, destinada ao magistério na educação infantil e nos anos iniciais do ensino fundamental, far-se-á, preferencialmente, em cursos normais superiores (BRASIL, 2000, Art. $1^{\circ}$ ).

Assim, o que anteriormente expressava a obrigatoriedade - "exclusivamente em cursos normais superiores" (BRASIL, 1999b, Art. $3^{\circ}, \S 2^{\circ}$ ) - da formação em nível superior, foi redefinido para algo meramente preferencial, o que no caso denotava a exigência da formação apenas quando possível. Nota-se, que, com essa alteração, a meta estabelecida no art. $87, \S 4^{\circ}$ não foi revogada ou excluída da LDB.

A LDB também trazia em seu artigo 87 que:

A União, no prazo de um ano a partir da publicação desta Lei, encaminhará, ao Congresso Nacional, o Plano Nacional de Educação, com diretrizes e metas para os dez anos seguintes, em sintonia com a Declaração Mundial sobre Educação para Todos (BRASIL, 1996a, Art. 87, § 1º).

Apresentado na Câmara Federal em 10 de fevereiro de 1998, o projeto tramitou até o ano de 2001, quando foi promulgada a Lei $\mathrm{n}^{\mathrm{o}}$ 10.172, de 09 de janeiro de 2001 (BRASIL, 2001) que aprovou o Plano Nacional de Educação (PNE). No tópico Diagnóstico (10.1) do item 10 do PNE, Formação dos professores e valorização do magistério, constava: "Para as 4 [quatro] primeiras séries do ensino fundamental: 94.976 precisam obter diploma de nível médio, modalidade normal". No tópico Objetivos e Metas (10.3) do mesmo capítulo 10 (item 18), lêse:

Garantir, por meio de um programa conjunto da União, dos Estados e Municípios, que, no prazo de dez anos, $70 \%$ dos professores de educação infantil e de ensino fundamental (em todas as modalidades) possuam formação específica de nível superior, de licenciatura plena em instituições qualificadas.

Por sua vez, o Parecer no 1 do Conselho Nacional de Educação (CNE), de 19 de fevereiro de 2003 (BRASIL, 2003), esclarecia que:

Os portadores de diploma de nível médio, bem como os que vieram a obtê-lo sob a égide da Lei $\mathrm{n}^{\circ}$ 9394/96, têm direito assegurado (e até o fim de suas vidas) ao exercício profissional do Magistério nas turmas de Educação Infantil ou nas séries iniciais do Ensino Fundamental, conforme a sua habilitação. 
Em 2006, o $\mathrm{CNE}^{5}$, por meio da Resolução CNE/CP n ${ }^{0}$ 1, de 15 de maio de 2006 definiu o curso de Pedagogia como a única graduação para a atuação na educação infantil e nos primeiros anos do ensino fundamental (BRASIL, 2006, Art. $4^{\circ}$ ) que deveria ser ofertada nas instituições de ensino superior. A mesma resolução faz referência ao curso Normal de nível médio (Art. $2^{\circ}, 4^{\circ}$ e $9^{\circ}$ ). Conforme aponta o artigo 11 do documento:

As instituições de educação superior que mantêm cursos autorizados como Normal Superior e que pretenderem a transformação em curso de Pedagogia e as instituições que já oferecem cursos de Pedagogia deverão elaborar novo projeto pedagógico, obedecendo ao contido nesta Resolução (BRASIL, 2006, Art. 11).

Destaca-se que o Plano de Metas Compromisso Todos pela Educação, de 2007 (BRASIL, 2007), não faz referências específicas à formação docente ${ }^{6}$.

A Portaria CNE/CP n ${ }^{\text {0 }}$ 10, de 6 de agosto de 2009 (BRASIL, 2009), com "Indicações para subsidiar a construção do Plano Nacional de Educação 2011 - 2020" apontava no terceiro item do tópico 2.17 Prioridades para Formação dos Profissionais: "Estabelecer um prazo para extinguir o curso normal de nível médio no País, para que ele deixe de ser considerado como formação inicial do professor e, consequentemente, como patamar básico de remuneração".

Em 2011, ano do término do decênio do PNE (BRASIL, 2001), o número de professores dos anos iniciais do ensino fundamental com diploma de nível superior saltou para 68,16\% (INEP, 2012), pouco abaixo da meta estabelecida. Em 2013, após dezessete anos da publicação da LDB (BRASIL, 1996) e doze anos do PNE (BRASIL, 2001), o número de professores dos anos iniciais do ensino fundamental com diploma havia saltado para 71,08\% (INEP, 2014).

O Plano Nacional da Educação de 2001, válido até 2011, deveria ser substituído por um novo PNE a partir dessa data. Vale ressaltar que, apesar do artigo 214 da Constituição Federal (CF) de 1988 (BRASIL, 1988) definir que "A lei estabelecerá o plano nacional de educação, de duração plurianual [...]”, foi somente por meio da LDB (BRASIL, 1996a, Art. 87, § $1^{\circ}$ ) e do PNE de 2001 (BRASIL, 2001, Art. $1^{\circ}$ ) que se regulamentou o período de validade de cada PNE para dez anos, alteração incorporada na CF por meio da Emenda Constitucional n ${ }^{0} 59$, de 11 de novembro de 2009. Em portaria de 6 de agosto de 2009 (BRASIL, 2009), o Conselho Nacional de Educação (CNE) definia que: "Todas as indicações presentes nesse documento deverão nortear a construção do PNE (2011-2020) [...]”. Ocorre que um novo Plano Nacional da

${ }^{5}$ Apesar de o PNE citar como fonte a Sinopse Estatística da Educação Básica 1996 do MEC, o dado refere-se à Sinopse Estatística da Educação Básica 1998 (INEP, 1996; 1998).

${ }^{6}$ Consta no Art. $2^{\circ}$, inciso XII: "Instituir programa próprio ou em regime de colaboração para formação inicial e continuada de profissionais da educação".

RPGE- Revista on line de Política e Gestão Educacional, Araraquara, v. 24, n. 3, p. 1461-1473, set./dez. 2020. e-ISSN:1519-9029 DOI: https://doi.org/10.22633/rpge.v24i3.13597 
Educação só foi aprovado com a publicação da Lei no 13.005, em 25 de junho de 2014, para vigorar no decênio 2014-2024. Dentre as metas apresentadas no PNE de 2014, consta:

Meta 15: garantir, em regime de colaboração entre a União, os Estados, o Distrito Federal e os Municípios, no prazo de 1 (um) ano de vigência deste PNE, política nacional de formação dos profissionais da educação de que tratam os incisos I, II e III do caput do art. 61 da Lei no 9.394, de 20 de dezembro de 1996, assegurado que todos os professores e as professoras da educação básica possuam formação específica de nível superior, obtida em curso de licenciatura na área de conhecimento em que atuam (BRASIL, 2014).

Tal indefinição corrobora a decisão anterior do governo brasileiro de revogar, por meio da Lei ${ }^{\circ}$ 12.796/2013 (BRASIL, 2013), o trecho da LBD (BRASIL, 1996a, Art. 87, § $4^{\circ}$ ) onde se lia: “Até o fim da Década da Educação somente serão admitidos professores habilitados em nível superior ou formados por treinamento em serviço". Ou seja, após findado o prazo da meta estabelecida pela LDB e não obtendo êxito em seu cumprimento, decidiu-se pela exclusão do trecho da lei. Assim, ressaltou-se que, apesar de o país possuir metas que visam assegurar a formação de todos os professores em nível superior, não há o estabelecimento de prazos para o seu cumprimento.

A Lei $\mathrm{n}^{\circ} 12.796$ (BRASIL, 2013) também modificou o artigo 62 da LDB, que passou a vigorar com o seguinte texto:

A formação de docentes para atuar na educação básica far-se-á em nível superior, em curso de licenciatura, de graduação plena, em universidades e institutos superiores de educação, admitida, como formação mínima para o exercício do magistério na educação infantil e nos 5 (cinco) primeiros anos do ensino fundamental, a oferecida em nível médio na modalidade normal.

Com isso, manteve-se a admissão de professores com formação de nível médio na modalidade normal ${ }^{7}$ para o magistério nos primeiros anos do ensino fundamental. Sobre isso, aponta BARRETTO (2015, p. 693):

O evidente teor conservador da medida não só se manifesta em termos da própria concepção da formação docente necessária ao atendimento das necessidades educacionais da população em todos os níveis do sistema educativo, como em relação ao esforço realizado pelo país para alçar o magistério a um novo patamar, em consonância com as tendências mundiais. Mas ele também retorna a um padrão conhecido das políticas de educação: o de legitimar as medidas emergenciais como permanentes!

7 Em 2015 havia 1.137 estabelecimentos de ensino que ofertavam o Ensino Médio na modalidade Normal/Magistério, com um total de 93.919 matrículas (INEP, 2016, tabelas 1.1 e 3.1).

RPGE- Revista on line de Política e Gestão Educacional, Araraquara, v. 24, n. 3, p. 1461-1473, set./dez. 2020. e-ISSN:1519-9029 DOI: https://doi.org/10.22633/rpge.v24i3.13597 
Para a autora há, também, um componente econômico e político: com um maior contingente de professores sem formação de nível superior, não há aumento da despesa com as folhas salariais, “[...] uma vez que a Lei do Piso Salarial do Magistério [Lei n 11.738, de 16 de julho de 2008] fixou com base nos proventos de profissionais com formação de nível médio (BARRETTO, 2015, p. 693).

Por sua vez, o PNE para o decênio 2014-2024 (BRASIL, 2014) tem como uma de suas metas:

15.9) implementar cursos e programas especiais para assegurar formação específica na educação superior, nas respectivas áreas de atuação, aos docentes com formação de nível médio na modalidade normal, não licenciados ou licenciados em área diversa da de atuação docente, em efetivo exercício; (BRASIL, 2014, meta 15.9).

Em 2017, por meio da Lei $n^{0} 13.415$ (BRASIL, 2017), ocorreu a última alteração no artigo 62 da LBD, dando a sua configuração atual. Conforme apontam Lima e Maciel (2018, p. 9), referida lei “materializou a reforma do ensino médio do Governo Temer", o que afetou direta ou indiretamente toda a educação básica. $\mathrm{O}$ artigo passou a vigorar com o seguinte texto:

A formação de docentes para atuar na educação básica far-se-á em nível superior, em curso de licenciatura plena, admitida, como formação mínima para o exercício do magistério na educação infantil e nos cinco primeiros anos do ensino fundamental, a oferecida em nível médio, na modalidade normal (BRASIL, 2017, Art. $7^{\circ}$ ).

Tem-se que, as exigências atuais para a formação e atuação de professores nos anos iniciais do ensino fundamental, possuem - após tantas promessas não cumpridas presentes na legislação (BRASIL, 1996; 2001; 2014) - diretrizes muito semelhantes aquelas presentes na LDB promulgada há mais de duas décadas. As duas diferenças a serem ressaltadas são: a exclusão da exigência de formação superior em universidades e institutos superiores de educação, posto que há um leque maior de instituições formadoras; e a desnecessária inclusão da expressão "licenciatura plena", visto que as licenciaturas curtas foram extintas pela LBD de 1996, conforme ressaltado pela Resolução CES nº 2, de 19 de maio de 1999 (BRASIL, 1999d).

\section{Considerações finais}

Com as diversas alterações aqui citadas sobre as exigências para a atuação dos professores nos anos iniciais do ensino fundamental, tem-se que a legislação educacional brasileira vem, desde a Lei de Diretrizes e Bases de 1996, se adequando à realidade e ao 
contexto social e econômico do país, inferindo sobre as estratégicas de políticas públicas educacionais que não foram eficazes. Segundo Nader (2012, p. 18), “As instituições jurídicas são inventos humanos que sofrem variações no tempo e no espaço. Como processo de adaptação social, o Direito deve estar sempre se refazendo, em face da mobilidade social [...]”. Nesse sentido, Gatti et al. (2019, p. 32) afirmam que:

O que observamos é que sempre houve, e até hoje há no país, improvisações para suprir a expansão das escolas com professores. Nota-se no tempo escolhas em políticas educacionais um tanto equivocadas, esquecidas das necessidades de docentes adequadamente formados para que reformas educacionais e currículos propostos realmente pudessem ser realizados em seus propósitos nas práticas educativas escolares.

Conforme apontado na Figura 2, no período de 1996 até 2019 o número de docentes nos anos iniciais do ensino fundamental teve pequenas variações em cada quadriênio, mantendo-se estável. Houve um significativo aumento no número de professores com ensino superior.

Figura 2 - Quadro do número de funções docentes (1996-2004) e de professores (2008-2009) nos anos iniciais do ensino fundamental por escolaridade

\begin{tabular}{|c|c|c|c|c|c|}
\hline & $\begin{array}{c}\text { Ensino } \\
\text { Fundamental } \\
\text { incompleto }\end{array}$ & $\begin{array}{c}\text { Ensino } \\
\text { Fundamental }\end{array}$ & $\begin{array}{c}\text { Ensino } \\
\text { Médio/Normal } \\
\text { Médio }\end{array}$ & Ensino Superior & Total \\
\hline $\mathbf{1 9 9 6}$ & $\begin{array}{c}8,15 \% \\
(63.257)\end{array}$ & $\begin{array}{c}7,11 \% \\
(55.225)\end{array}$ & $\begin{array}{c}64,42 \% \\
(500.238)\end{array}$ & $\begin{array}{c}20,32 \% \\
(157.817)\end{array}$ & 776.537 \\
\hline $\mathbf{2 0 0 0}$ & $2,67 \%$ & $\begin{array}{c}5,46 \% \\
(21.774)\end{array}$ & $\begin{array}{c}67,29 \% \\
(548.469)\end{array}$ & $\begin{array}{c}24,58 \% \\
(200.326)\end{array}$ & 815.079 \\
\hline $\mathbf{2 0 0 4}$ & $0,32 \%$ & $\begin{array}{c}1,07 \% \\
(2.633)\end{array}$ & $\begin{array}{c}57,841) \\
(469.5 \%\end{array}$ & $\begin{array}{c}41,53 \% \\
(341.637)\end{array}$ & 822.708 \\
\hline $\mathbf{2 0 0 8}$ & Não consta ${ }^{1}$ & $\begin{array}{c}0,65 \% \\
(4.669)\end{array}$ & $\begin{array}{c}39,11 \% \\
(280.555)\end{array}$ & $\begin{array}{c}60,24 \% \\
(432.108)\end{array}$ & 717.332 \\
\hline $\mathbf{2 0 1 2}$ & Não consta & $\begin{array}{c}0,31 \% \\
(2.344)\end{array}$ & $\begin{array}{c}31 \% \\
(231.811)\end{array}$ & $\begin{array}{c}68,69 \% \\
(513.557)^{2}\end{array}$ & 747.712 \\
\hline $\mathbf{2 0 1 6}$ & Não consta & $\begin{array}{c}0,23 \% \\
(1.787)\end{array}$ & $\begin{array}{c}24,77 \% \\
(189.186)\end{array}$ & $\begin{array}{c}75 \% \\
(572.954)^{3}\end{array}$ & 763.927 \\
\hline $\mathbf{2 0 1 9}$ & Não consta & $\begin{array}{c}0,21 \% \\
(1.615)\end{array}$ & $\begin{array}{c}15,54 \% \\
(116.838)\end{array}$ & $\begin{array}{c}84,25 \% 4 \\
(633.541)\end{array}$ & 751.9945 \\
\hline
\end{tabular}

*Até 2006 contava-se a função docente, ou seja, o mesmo professor podia "ser contado mais de uma vez no exercício de suas atribuições como regente de classe" (INEP, 2007). A partir de então, "na Sinopse sobre o Professor 2007 se privilegia a produção de dados relativos ao número de professores" (INEP, 2007). Por isso a diferença significativa entre os dados totais dos anos de 2004 e 2008 aqui apresentados.

** As sinopses estatísticas da educação básica produzidas pelo INEP não especificam tratar-se do Ensino Médio regular ou Curso Normal na modalidade médio.

${ }^{1}$ Em 2006, último ano a constar essa informação, havia 1.675 funções docentes (ou 0,2\% do total) com Ensino Fundamental incompleto.

${ }^{2}$ Destes, 19.232 (ou $2,57 \%$ do total de professores) não possuem licenciatura.

${ }^{3}$ Destes, 13.617 (ou $1,78 \%$ do total de professores) não possuem licenciatura.

${ }^{4}$ Destes, 31.166 (ou $4,14 \%$ do total de professores) não possuem licenciatura.

${ }^{5}$ Destes, 10,6\% com formação de Ensino Médio Normal/Magistério (INEP, 2020c, p. 22).

Fonte: INEP, 2020b (Sinopses Estatísticas da Educação Básica 1996-2019): 1996 (tabela 2.5); 2000 (tabela 2.10); 2004 (tabela 2.8); 2006 (tabela 2.12); 2007; 2008 (tabela 6.5); 2012 (tabela 2.23); 2016 (tabela 2.23); 2019 (tabela 2.23).

Fonte: INEP (2007) - adaptado pelos autores 
Por outro lado, nos sucessivos governos pós-LDB, a legislação foi sendo permeada por exigências (de formação) aos professores enquanto o próprio Estado brasileiro não conseguiu suprir a necessidade de instituições formadoras. Dito de outra forma, o Estado brasileiro criou as expectativas por meio das exigências de formação e de supostos planejamentos de longo prazo para, depois, com o não cumprimento de seu papel, relativizar suas próprias exigências.

Figura 3 - Publicidade do governo de Mato Grosso do Sul (2019)

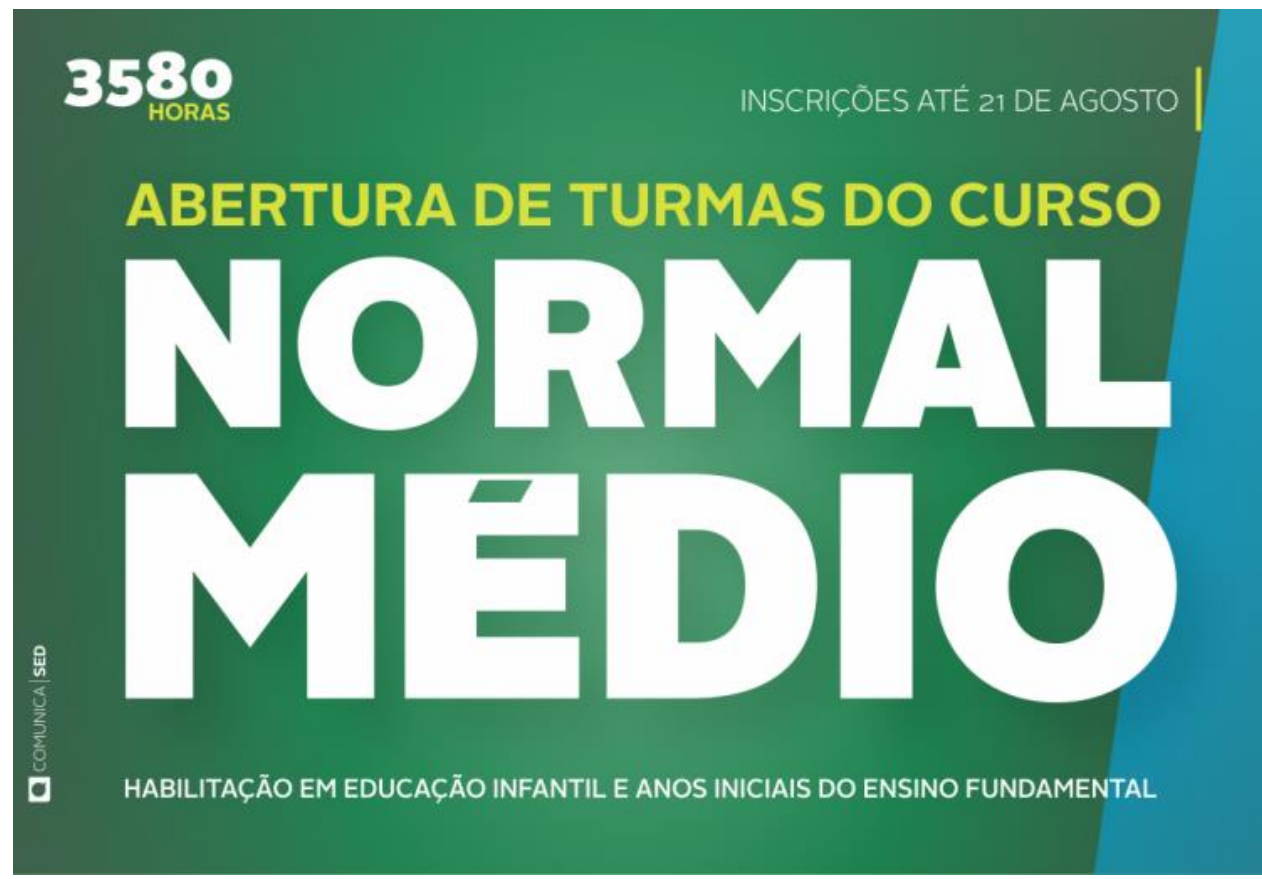

Fonte: Secretaria de Estado de Educação de Mato Grosso do Sul ${ }^{8}$

O Curso Normal Médio/Magistério continua sendo oferecido nas redes pública e privada. Em 2019 (INEP, 2020b, tabelas 1.30, 3.19 e 4.14), ano do último Censo da Educação Básica, havia 2.583 turmas de Ensino Médio Normal/Magistério distribuídas por 692 estabelecimentos de ensino com 64.222 alunos matriculados.

\section{REFERÊNCIAS}

BARRETTO, E. S. S. Políticas de formação docente para a educação básica no Brasil: embates contemporâneos. Rev. Bras. Educ., Rio de Janeiro, v. 20, n. 62, p. 679-701, set. 2015. Disponível em: http://www.scielo.br/scielo.php?script=sci_arttext\&pid=S141324782015000300679\&lng=en\&nrm=iso. Acesso em: 8 abr. 2020.

${ }^{8}$ Publicado em 20 ago. 2019. Disponível em: https://www.sed.ms.gov.br/inscricoes-para-curso-normal-medioencerram-nesta-quarta-feira/. Acesso em: 07 abr. 2020.

RPGE- Revista on line de Política e Gestão Educacional, Araraquara, v. 24, n. 3, p. 1461-1473, set./dez. 2020. e-ISSN:1519-9029 DOI: https://doi.org/10.22633/rpge.v24i3.13597 
BRASIL. Conselho Nacional de Educação. Parecer CNE/CEB n. 1, de 19 de fevereiro de 2003. Consulta sobre formação de profissionais para a Educação Básica. Brasília: CNE, 2003. Disponível em: http://portal.mec.gov.br/cne/arquivos/pdf/pceb001_03.pdf. Acesso em: 20 abr. 2020.

BRASIL. Conselho Nacional de Educação. Parecer CNE/CES n. 970, de 9 de novembro de 1999. Curso Normal Superior e da Habilitação para Magistério em Educação Infantil e Séries Iniciais do Ensino Fundamental nos cursos de Pedagogia. Brasília: CNE, 1999c. Disponível em: http://portal.mec.gov.br/component/content/article?id=13245:parecer-ces-1999. Acesso em: 6 abr. 2020.

BRASIL. Conselho Nacional de Educação. Parecer CNE/CP n. 1, de 15 de maio de 2006. Institui Diretrizes Curriculares Nacionais para o Curso de Graduação em Pedagogia, licenciatura. Brasília: CNE, 2006. Disponível em:

http://portal.mec.gov.br/cne/arquivos/pdf/rcp01_06.pdf. Acesso em: 6 abr. 2020.

BRASIL. Conselho Nacional de Educação. Portaria CNE/CP n. 10, de 6 de agosto de 2009. Indicações para subsidiar a construção do Plano Nacional de Educação 2011-2020. Brasília: CNE, 2009. Disponível em: http://portal.mec.gov.br/dmdocuments/pne_200809.pdf. Acesso em: 6 abr. 2020.

BRASIL. Conselho Nacional de Educação. Resolução CEB n. 2, de 19 de abril de 1999. Institui Diretrizes Curriculares Nacionais para a Formação de Docentes da Educação Infantil e dos anos iniciais do Ensino Fundamental, em nível médio, na modalidade Normal. Diário Oficial da União: Seção 1, Brasília: CNE, p. 97, 23 abr. 1999a.

BRASIL. Decreto n. 3.276, de 6 de dezembro de 1999. Dispõe sobre a formação em nível superior de professores para atuar na educação básica, e dá outras providências. Diário Oficial da União: Seção 1, Brasília, p. 4, 1999b.

BRASIL. Decreto n. 3.554, de 7 de agosto de 2000. Dá nova redação ao $\S 20$ do art. 3o do Decreto no 3.276, de 6 de dezembro de 1999, que dispõe sobre a formação em nível superior de professores para atuar na educação básica, e dá outras providências. Diário Oficial da União: Seção 1, Brasília, p. 1, 8 ago. 2000.

BRASIL. Decreto n. 6.094, de 24 de abril de 2007. Dispõe sobre a implementação do Plano de Metas Compromisso Todos pela Educação [...]. Brasília, 25 abr. 2007. Disponível em: http://www.planalto.gov.br/ccivil_03/_Ato2007-2010/2007/Decreto/D6094.htm. Acesso em: 6 abr. 2020.

BRASIL. Lei n. 10.172, de 9 de janeiro de 2001. Aprova o Plano Nacional de Educação e dá outras providências. Diário Oficial da União: Seção 1, Brasília, DF: Câmara dos Deputados, p. 1, 10 jan. 2001. PL 4155/1998

BRASIL. Lei n. 12.796, de 4 de abril de 2013. Altera a Lei no 9.394, de 20 de dezembro de 1996, que estabelece as diretrizes e bases da educação nacional, para dispor sobre a formação dos profissionais da educação e dar outras providências. Diário Oficial da União: Seção 1, Brasília, DF, p. 1, 5 abr. 2013. 
BRASIL. Lei n. 13.005, de 25 de junho de 2014. Aprova o Plano Nacional de Educação PNE e dá outras providências. Diário Oficial da União: Seção 1, Brasília, DF, p. 1, 26 jun. 2014. PL 8035/2010

BRASIL. Lei n. 13.415, de 16 de fevereiro de 2017. Altera as Leis $n^{\circ}$ s. 9.394, de 20 de dezembro de 1996, que estabelece as diretrizes e bases da educação nacional [...]. Diário Oficial da União: Seção 1, Brasília, DF, p. 1, 17 fev. 2017.

BRASIL. Lei n. 9.394, de 20 de dezembro de 1996. Estabelece as diretrizes e bases da Educação Nacional. Diário Oficial da União: Seção 1, Brasília, DF: MEC, p. 27833, 23 dez. 1996. PL 1258/1988

BRASIL. Lei n. 9.424, de 24 de dezembro de 1996. Dispõe sobre o Fundo de Manutenção e Desenvolvimento do Ensino Fundamental e de Valorização do Magistério [...]. Diário Oficial da União: Seção 1, Brasília, p. 28442, 26 dez. 1996b.

BRASIL. Resolução CES no 2 , de 19 de maio de 1999. Dispõe sobre a plenificação de licenciaturas curtas por faculdades e faculdades integradas no sistema federal de ensino. Brasília, 20 maio1999d. Disponível em: http://portal.mec.gov.br/cne/arquivos/pdf/rces02_99.pdf. Acesso em: 06 abr. 2020.

GATTI, B. A.; BARRETTO, E. S. S.; ANDRÉ, M. E. D. A.; ALMEIDA, P. C. A. Professores do Brasil: novos cenários de formação. Brasília: UNESCO, 2019.

INEP. Instituto Nacional De Estudos E Pesquisas Educacionais Anísio Teixeira. Sinopses Estatísticas da Educação Superior. Brasília: Inep, 2000a. Disponível em: http://inep.gov.br/web/guest/sinopses-estatisticas-da-educacao-superior. Acesso em: 6 abr. 2020 .

INEP. Instituto Nacional De Estudos E Pesquisas Educacionais Anísio Teixeira. Sinopses Estatísticas da Educação Básica. Brasília: Inep, 2000b. Disponível em: http://inep.gov.br/sinopses-estatisticas-da-educacao-basica. Acesso em: 6 abr. 2020.

INEP. Instituto Nacional De Estudos E Pesquisas Educacionais Anísio Teixeira. Censo da Educação Básica 2019: Notas estatísticas. Brasília: INEP, 2020c. Disponível em: $\mathrm{http} / / /$ portal.inep.gov.br/informacao-da-publicacao//asset_publisher/6JYIsGMAMkW1/document/id/6798882. Acesso em: 7 abr. 2020.

LIMA, Marcelo; MACIEL, Samanta Lopes. A reforma do Ensino Médio do governo Temer: corrosão do direito à educação no contexto de crise do capital no Brasil. Rev. Bras. Educ., Rio de Janeiro, v. 23, 2018. Disponível em:

http://www.scielo.br/scielo.php?script=sci_arttext\&pid=S141324782018000100245\&lng=en\&nrm=iso. Acesso em: 6 abr. 2020.

NADER, P. Introdução ao Estudo do Direito. 34. ed. Rio de Janeiro: Forense, 2012.

PINHEIRO, G. C. G.; ROMANOWSKI, J. P. Curso de pedagogia: formação do professor da educação infantil e dos anos séries iniciais do ensino fundamental. Revista Formação Docente, Belo Horizonte, v. 2, n. 3, p. 136-151, ago./dez. 2010. Disponível em: https://revformacaodocente.com.br/index.php/rbpfp/article/view/23. Acesso em: 13 abr. 2020. 


\section{Como referenciar este artigo}

SUFICIER, D. M.; AZADINHO, M. P. M.; MUZZETI, L. R. Exigências legais para a atuação de professores nos anos iniciais do ensino fundamental (1996-2019). Revista on line de Política e Gestão Educacional, Araraquara, v. 24, n. 3, p. 1461-1473, set./dez. 2020. eISSN:1519-9029. DOI: https://doi.org/10.22633/rpge.v24i3.13597

Submetido em: 19/04/2020

Revisões requeridas: $18 / 06 / 2020$

Aprovado em: $27 / 07 / 2020$

Publicado em: 01/09/2020 